\title{
LESÃO HEPÁTICA E POLIFARMÁCIA: UM RELATO DE CASO
}

\author{
HEPATIC INJURY AND SELF-MEDICATION: A CASE REPORT
}

Marcos Antonio Cavalari de Souza*, Lucas Moreira Guerra, Beatriz Teixeira Rondina, Thatiana Scalon, Caio Cardozo Jorge, Nilo David Paro.

Centro Universitário das Faculdades Associadas de Ensino, São João da Boa Vista, SP, Brasil.

*marcos.macaubal2015@gmail.com

\section{RESUMO}

Muitos fármacos frequentemente causam elevações assintomáticas de enzimas hepáticas devido sua farmacocinética e metabolização hepática. Entretanto, hepatite aguda por droga clinicamente significante ou piora nos parâmetros de função hepática é rara. A lesão hepática induzida por medicamentos - DILI (Drug Induced Liver Injury) pode ser definida como lesão no fígado causada por medicação ou toxina que levem a anormalidades em exames laboratoriais hepáticos, e sua apresentação clínica pode ir de assintomática à falência hepática. O tratamento da DILI baseia-se na abstinência precoce do fármaco e tratamento secundário das possíveis lesões hepáticas; em casos graves, o transplante de fígado poderá ser uma opção terapêutica. No relato, encontra-se paciente masculino, 45 anos, apresentando quadro intenso de icterícia generalizada em face, tronco, abdome e membros. Acompanham acompanhada de colúria, dor em região epigástrica e de hipocôndrio direito, inapetência e constipação. Ao interrogatório sintomatológico nega outras queixas. Antecedentes pessoais: Diabetes Mellitus 2 há 10 anos em uso de Metformina e Glicasida, epilepsia há 25 anos em tratamento com trileptal, ácido valproico e clonazepan, tireoidectomia há 13 anos em uso de Puran T4, transtorno depressivo maior há 10 anos em uso de sertralina, fibromialgia há 10 anos em uso de amitriptilina. Refere quadro de pneumonia há 12 dias, tendo realizado tratamento com amoxicilina com clavulanato por 7 dias, terminando o seu uso há 5 dias. Ao exame físico apresentou abdome distendido, ausculta com ruídos hidroaéreos intensos, percussão timpânica, traube maciça, palpação com dor em hipocôndrio direito e região epigástrica e fígado palpável $8 \mathrm{~cm}$ do RCD e baço palpável em $4 \mathrm{~cm}$ do RCE. Exames sorológicos de hepatites virais negativo. Tomografia computadorizada demonstrou hepatoesplenomegalia. Exames laboratoriais com: TGO o dobro do normal para idade e sexo, TGP elevado em três vezes, FA elevado em quatro vezes. Acompanhado em internação hospitalar por 11 dias. Prescrição inicial de Buscopan, Bromoprida, Lactulona, Ácido valprocoico, Puran T4, Ranitidina, Dextro de 12/12h, Insulina conforme protocolo do serviço. Ao $11^{\circ}$ dia recebeu alta hospitalar, com ajuste de dosagens e prescrições. Dessa forma, conclui-se que dentro os medicamentos mais prevalentes nas hepatites medicamentosas, está presente a amoxicilina com clavulanato, a qual o paciente fez uso. A real incidência de hepatopatia farmacoinduzida é difícil de ser determinada, pois na maioria das vezes essas alterações são assintomáticas e passam despercebidas. Em muitas situações, o atendimento médico somente é procurado se a sintomatologia for extrema. Vale 
ressaltar que o paciente acima somente procurou assistência quando o quadro ictérico estava muito acentuado, de modo que a sua assistência se iniciasse tardiamente ocasionando maiores consequências.

Palavras-chave: Combinação amoxicilina e clavulanato de potássio. Doença hepática crônica induzida por substâncias e drogas. Hepatomegalia. Icterícia. Polimedicação. 